\title{
The Implications of Adjunct Faculty on Higher Education Institutions
}

\author{
Dr. Reem Alsunaydi \\ The University of the Incarnate Word, School of Education, San Antonio, Texas
}

\begin{abstract}
An adjunct is a part-time instructor paid per course or on an hourly basis. Over the past 40 years, the practice of hiring adjunct or part-time faculty has seen a significant shift in higher education in the United States across all institution types. Increased and continuing reliance on adjuncts have raised concerns about the implications for students, faculty, institutions' missions, and other vital strategic aspects. With limited resources and increasing demands for accountability institutional leaders need to evaluate their policies and practices regarding hiring adjuncts to ensure the effective and efficient use of their resources without affecting academic quality. The paper identifies the reasons for this shift and examines the benefits of hiring adjuncts and its impact on students. The implications on governance, autonomy, and academic freedom are discussed and described. The paper also examines some of the legal and ethical considerations - as well as the leadership and financial considerationsinvolved in hiring adjuncts. Finally, the paper provides recommendations for educational leaders to consider when reviewing their institutions polices for faculty, including adjuncts.
\end{abstract}

Keywords: adjunct faculty, higher education, administration, educational leaders

DOI: $10.7176 / \mathrm{JEP} / 11-32-13$

Publication date: November $30^{\text {th }} 2020$

\section{Reasons for the Shift}

From 1993 to 2013, the number of adjunct faculty in higher education institutions underwent a major increase of $104 \%$. In comparison, the number of full-time faculty only increased by $45 \%$ (National Center for Education Statistics, 2015). In 2013, approximately $43 \%$ of higher education faculty worked on a part-time basis (Finkelstein, Conley \& Schuster, 2017). The growing use of part-time faculty has been mostly at community colleges. Adjuncts have become key stakeholders and play an important role at community colleges as they teach the majority of the courses (Datray, Saxon \& Martirosyan, 2014).

One important reason for the shift is the reductions in state and local funding over the last few decades across the United States. Another reason is institutions' need to adapt to enrollment growth. From 2000 to 2010 , undergraduate enrollment increased by $30 \%$ at public institutions and by $20 \%$ at private non-profit institutions. Even though enrollment growth has slowed in recent years, it is expected to increase by more than $10 \%$ by 2024 (Snyder, de Brey \& Dillow, 2016). Institutions have adapted to this by hiring more adjuncts to limit the costs of hiring more full-time faculty. In addition, online education is growing rapidly, with 6.5 million distance education students in 2016 (Allen \& Seaman, 2015). Again, institutional leaders have addressed this growth via heavy reliance on adjuncts to oversee these digital programs (Ridge \& Ritt, 2017).

\section{The Advantages of Employing Adjunct Faculty}

As a result of the recent economic recession, many institutions have experienced a persistent decline in state funding (Blumenstyk, 2015). Therefore, many have chosen to hire adjuncts in undergraduate and graduate programs as a feasible strategy to decrease costs because adjuncts are paid less and receive fewer benefits than tenure/full-time faculty (Brennan \& Magness, 2018). Approximately 70-80\% of an institution's budget goes toward faculty salaries and benefits (Archibald \& Feldman, 2008). Because adjuncts are, on average, 80\% less expensive than full-time faculty, hiring them is considered to be an appropriate strategy to face the current economic challenges (Bettinger \& Long, 2010).

Hiring adjuncts also provides institutional leaders with greater flexibility in scheduling and canceling courses based on enrollment fluctuations (Gappa, Austin \& Trice, 2007). Adjuncts can fill in as substitutes for full-time faculty who cannot teach when they are working on research or must take leaves of absence (Thedwall, 2008). Adjuncts benefit students, as they bring recent knowledge and diverse experiences in their subjects that tenured faculty may not have (Brennan \& Magness, 2018; Langen, 2011).

\section{Adjunct Faculty's Impact on Students}

A major criticism of hiring adjuncts is that they might have a negative impact on the quality and effectiveness of teaching (Bolitzer, 2019). Researchers have found that adjuncts have less time to prepare for their courses and utilize less effective teaching techniques in comparison with full-time faculty (Benjamin, 2002; Bolitzer, 2019; Umbach, 2007). In addition, adjuncts were found to have less interaction with students than full-time faculty such as in advising students (Umbach, 2007). Sandhoff (2018) indicated that new adjuncts were less likely to 
incorporate learning theories compared to tenured faculty due to a lack of professional development and guidance in dealing with adult students. Adults have different learning styles, needs, and interests, all of which affect their learning motivation and engagement, whether it be face-to-face or in online settings (Merriam \& Bierema, 2014). Although many adjuncts are experts in their fields, they may face difficulties in applying adult learning theories within online courses, especially adjuncts who do not have the proper training or experience in this teaching format (Sandhoff, 2018).

Adult learning theories such as constructivism, self-directed learning, transformational learning, and social development are important because they provide explanations for how adults differ in their learning and thinking from children. Understanding these theories and their applications helps faculty to facilitate the diverse needs of their students, use effective and active teaching strategies, and employ instructional design that leads to a deeper level of learning (Merriam \& Bierema, 2014). Therefore, institutional leaders should be aware that providing their faculty, including adjuncts, with ongoing professional development opportunities is crucial to fostering students' learning.

The lack of proper professional development can lead to several different problems. Previous researchers demonstrated that adjuncts tend to focus on content as a measure rather than helping their students to build critical thinking skills (Benjamin, 2002). They were also found to give higher grades than full-time faculty and to have lower standards for the quality of the students' work because of their concerns regarding students' evaluations (Jacoby, 2006; Umbach, 2007). Ehrenberg and Zhang (2005) examined the effect of adjuncts on graduation rates in four colleges and found a negative relationship between heavy reliance on adjuncts and graduation rates. Several researches also indicated a negative impact of adjuncts on student retention and student learning outcomes (Jaeger \& Hinz, 2009; Jacoby, 2006).

Tyndall (2017) provided a holistic view on the impact of adjunct teaching. The researcher stated that the relationship between students' academic performance and exposure to adjuncts instruction is complex. Lacking sufficient institutional support and resources might be the reason behind negative outcomes more than adjuncts lacking effective teaching capabilities. A national study conducted by Street et al. (2012) confirmed that adjuncts often lacked access to material and adequate resources for teaching, such as supplies, curriculum guidelines, technological equipment, and office space. Institutional leaders should be aware that these conditions may negatively affect adjuncts' performance, teaching self-efficacy, and subsequently, students' learning and successes (Bolitzer, 2019, Tyndall, 2017).

Moreover, the growth of global education has led to a rise in international students attending American higher education institutions. Institutional leaders must consider these students' diverse cultures and needs to foster their learning and success (Blumenstyk, 2015). Rogan (2017) found that one of the biggest challenges facing adjuncts was teaching and supporting international students. Cultural dimensions theories, such as those by Hofstede (2001) and Hall and Hall (1990), emphasize important factors like power distance, individualism/collectivism, masculinity/femininity, and high-context/low-content, all of which can help educators to understand other cultures' values, beliefs, and communication patterns (Gannon \& Pillai, 2016). Institutional leaders should provide intercultural training to the faculty who are expected to work with international students in areas such as communication, class structure, class discussion, assignment design, and adding an international perspective to their courses.

\section{Institutional Governance, Autonomy, and Academic Freedom}

Previous studies demonstrated that adjuncts rarely contribute to governance at the institutions where they teach. They are also excluded from faculty meetings, campus activities, and decision-making process (Kezar, Maxey \& Eaton, 2014), which could poses threat to faculty role in shared governance (Bradley, 2004) and contribute to adjuncts dissatisfaction (Bolitzer, 2019). Simplicio (2006) argued that the reason behind excluding adjuncts from shared governance is their insufficient knowledge of the institution's history, needs, and strategic direction.

Scheive (2014) compared adjuncts and full-time faculty members' participation in shared governance, concluding that adjuncts contributed less in all four categories that relate to shared governance: faculty committees, university committees, leadership positions, and presidential task forces. Scheive raised the question of "how leaders can ensure that shared governance is effective at their institution when a large portion of their faculty body is made up by adjunct" (p.3). Therefore, institutional leaders and governing boards should develop a communication and decision-making mechanism that incorporates and balances all stakeholders' input, including adjuncts, to effectively perform its missions of teaching, research, and public service as well as to ensure that all the institution's members are moving toward the same strategic goals.

With regard to academic freedom, adjuncts have less autonomy to develop their own course materials or initiate changes to the curriculum (Kezar, 2013; Kuvakas, 2018). Students' evaluations also play a major role in determining adjuncts' performance. As a result, adjuncts may hesitate to discuss controversial ideas within the classroom and prefer to give simple homework, which could be considered as a threat to academic freedom (Gappa 
et al., 2007). Institutional leaders should ensure that academic freedom is extended to all faculty. An example of this is at the University of Wisconsin-Madison, which guarantees academic freedom and free speech to both its full-time faculty and its adjuncts (Chapter15: Academic Freedom, n.d.).

\section{Legal and Ethical Considerations}

Unequal pay, lack of benefits, and poor working conditions may expose institutions to risk of becoming involved in lawsuit related to their employment practices (Kaplan \& Lee, 2014). leaders should develop the necessary legal expertise to avoid legal issues resulting from hiring part-time faculty.

Institutional leaders should build a positive culture and ethical climate through the establishment of policies and procedures that take care of all students and the faculty members' needs and expectations (Schein, 2004). Shapiro and Stefkovich (2002) advised educational administrators to use a multi-ethical paradigm approachwhich includes the ethics of justice, care, critique, and profession - when making institutional decisions. The authors argued the multi-ethical paradigm would help institutions to make wise decisions rather than depend on a single ethical approach. Understanding all four ethics and the ways they can be used together gives institutional leaders opportunities to acquire a deeper understanding of the moral concepts and principles that guide their decisions (Catacutan \& de Guzman, 2015).

\section{Leadership and Financial Considerations}

Given the continued growth of adjuncts, it is vital for higher education administrators to develop effective leaders who are able to support this growing population (Diegel, 2013). Although adjuncts bring many advantages to institutions, keeping them satisfied and motivated has been difficult. Previous studies have stated that adjuncts lack institutional support and resources (Bolitzer, 2019; Tyndall, 2017), feel disconnected from the institution, lack professional development opportunities (Kezar, 2013), and are dissatisfied with their employment conditions, all of which impact their performance (Bolitzer, 2019). In addition, some administrators are unaware of how their leadership may impact adjuncts' job satisfaction (Barnett, 2017). Research has shown that effective communication was lacking between adjuncts and departmental administrators, which was a source of dissatisfaction (Eagan, Jaeger \& Grantham, 2015; Waltman et al, 2012). Adjuncts may have different perceptions of administrators' leadership styles than full-time faculty because adjuncts tend to be less engaged and receive minimal support from their institutions (Caruth \& Caruth, 2013).

In order to maximize the impact of adjunct faculty, institutional leaders must act in a way that promotes adjunct faculty satisfaction and engagement, thus enhancing students' learning (Caruth \& Caruth, 2013). Barnett (2017) found a positive relationship between the transformational leadership style and the overall job satisfaction of online adjunct faculty. Administrators in higher education should be aware of the applications of different leadership styles that correspond with their issues. Hackman and Johnsons (2013) stated, "no single approach provides a universal explanation of leadership behavior, but each provides useful insights" (p. 73).

Furthermore, administrators should strategically develop hiring, retention, and support plans that reflect their institutions' mission, vision, values, program goals, and operating budget. A cost analysis, including opportunity, direct, and indirect costs, requires careful consideration from leaders when developing their strategies for adjuncts (Betts \& Sikorski, 2008). Key performance indicators can help administrators to shift their priorities, shape budget allocation, and cut or eliminate extra expenses (Bryson, 2018). For example, Tufts University, which has about 200 adjuncts, reached a new agreement in 2014 to balance the needs and priorities of adjuncts and the university. The new agreement includes a $22 \%$ increase in their pay. The school also provides health, retirement, and other benefits to adjuncts who teach three courses per year. Also, other non-classroom work such as mentoring and advising is compensated. Finally, Tufts has created a \$25,000 fund to provide adjuncts with professional development (Schneider, 2015).

\section{Conclusion and Recommendations}

Higher education institutions have significantly increased their hiring of adjuncts as a response to the different challenges they face. Previous studies demonstrated that adjuncts bring both advantages and disadvantages to students and institutions. In terms of the adjuncts themselves, several studies indicated that adjuncts are disconnected from their work environments due to a lack of resources and administrative support. Academic leaders should understand that institutional changes should be aligned with their schools' mission, vision, and strategic plan to ensure the proper allocation of resources to higher priorities. Strengthening educational quality and improving institutions with limited resources is a skill that academic leaders need to master. Many leaders view change via money only; however, considerable progress could be equally achieved through new ideas. Leaders within higher education must develop innovate strategies to address today's requirements of being different from competitors and to ensure their institutions thrive in the future rather than just survive. Based on the aspects discussed in this paper, I recommend that educational leaders consider the following when they review their institutions' policies regarding adjuncts: 
1. Reassess the hiring policies and working conditions related to adjuncts to align them with the mission and vision of the institutions and needs of the students they serve. Avoid last-minute hiring decisions so that adjuncts have time to prepare their course materials.

2. Provide new faculty orientation sessions that include information about the institution's and department's mission, vision, values, resources, services, department policies, and course structure.

3. Provide opportunities for professional development via learning the theories and best practices for teaching students, especially for adjuncts who do not have teaching experience. If there are adjuncts who teach online, training should include online teaching skills and online pedagogy.

4. Provide institutional support and opportunities for adjuncts to participate in department decision-making to foster their commitment to the school. Adjuncts should be included in department meetings and should be given office space.

5. Adopt an effective mentorship strategy to foster connection and collaboration between adjuncts and full-time faculty who have taught similar courses to share best practices.

6. Adopt ongoing evaluation and benchmark tools to identify adjuncts' strengths and areas for improvement. Also, survey and interview adjuncts to gain feedback on their challenges and needs.

\section{References}

Allen, I.E., \& Seaman, J. (2015). Grade level: Tracking online education in the United States. Babson Survey Research Group and Quahog Research Group, LLC. Retrieved from https://onlinelearningsurvey.com/reports/gradeincrease.pdf

Archibald, R. B., \& Feldman, D. H. (2008). Explaining increases in higher education costs. The Journal of Higher Education, 79(3), 268-295.

Barnett, D. E. (2017). The effect of leadership on the job satisfaction of online adjunct faculty at a for-profit university. Available from ProQuest Dissertations \& Theses Global.

Benjamin, E. (2002). How over-reliance on contingent appointments diminishes faculty involvement in student learning. Peer Review, 5(1), 4-10.

Bettinger, E., \& Long, B. (2010). Does cheaper mean better? The impact of using adjunct instructors on student outcomes. The Review of Economics and Statistics, 92(3), 598-613.

Betts, K., \& Sikorski, B. (2008). Financial bottom line: Estimating the cost of faculty-adjunct turnover and attrition for online programs. Online Journal of Distance Learning Administration, 11(1).

Blumenstyk, G. (2015). American higher education in crisis? What everyone needs to know. New York; NY.: Oxford University Press.

Bolitzer, L. A. (2019). What we know (and don't know) about adjunct faculty as teachers at four-year institutions. Review of Higher Education, 43(1), 113-142.

Bradley, G. (2004). Contingent faculty and the new academic labor system. Academe, 90(1), 28-31.

Brennan, J., \& Magness, P. (2018). Estimating the cost of justice for adjuncts: A case study in university business ethics. Journal of Business Ethics, 148(1), 155-168.

Bryson, J. M. 1. (2018). Strategic planning for public and nonprofit organizations: A guide to strengthening and sustaining organizational achievement. San Francisco; CA: Jossey-Bass Publishers.

Caruth, G., \& Caruth, D. (2013). Adjunct faculty: Who are these unsung heroes of academe? Current Issues in Education, 16(3), 1-9.

Catacutan, M. R. G., \& de Guzman, A. B. (2015). Ethical decision-making in academic administration: A qualitative study of college deans' ethical frameworks. The Australian Educational Researcher, 42(4), 483514.

Datray, J. L., Saxon, D. P., \& Martirosyan, N. M. (2014). Adjunct faculty in developmental education: Best practices, challenges, and recommendations. The Community College Enterprise, 20(1), 35-48.

Diegel , B .J. (2013). Perceptions of community college adjunct faculty and division chairpersons: Support, mentoring, and professional development to sustain academic quality. Community College Journal of Research and Practice, 37(8), 596-607.

Eagan, M., Jaeger, A., \& Grantham, A. (2015). Supporting the academic majority: Policies and

practices related to part-time faculty's job satisfaction. The Journal of Higher Education, 86(3), 448-480.

Ehrenberg, R. G., \& Zhang, L. (2005). Do tenured and tenure-track faculty matter? Journal of Human Resources, 40(3), 647-659.

Finkelstein, M. J., Conley, V. M., \& Schuster, J. H. (2017). Whither the faculty? Change: The Magazine of Higher Learning, 49(4), 43-51.

Gannon, M. \& Pillai, R. (2013). Understanding global cultures: Metaphorical journeys through 29 nations, clusters of nations, continents, and diversity (5th ed.). Thousand Oaks, CA: Sage Publications.

Gappa, J., Austin, A., \& Trice, A. (2007). Rethinking faculty work: Higher education's strategic imperative (1st ed.). San Francisco, CA: Jossey-Bass. 
Hackman, M. Z., \& Johnson, C. E. (2013). Leadership: A communication perspective (6th ed.). Long Grove, IL: Waveland Press.

Jacoby, D. (2006). Effects of part-time faculty employment on community college graduation rates. The Journal of Higher Education, 77(6), 1081-1103.

Jaeger, A. J., \& Hinz, D. (2009). The effects of part-time faculty on first semester freshmen retention: A predictive model using logistic regression. Journal of College Student Retention, 10 (3), 265-286.

Kaplin, W. A., \& Lee, B. A. (2014). The law of higher education (5th ed.). San Francisco, CA: Jossey-Bass.

Kezar, A. (2013). Examining nontenure track faculty perceptions of how departmental policies and practices shape their performance and ability to create student learning at four-year institutions. Research in Higher Education, 54(5), 571-598.

Kezar, A., Maxey, D., \& Eaton, J. (2014). An examination of the changing faculty: Ensuring institutional quality and achieving desired student learning outcomes. Retrieved from https://www.chea.org/userfiles/Occasional\%20Papers/Examination_Changing Faculty 2013.pdf

Kuvakas, K. (2018). Examining the factors that impact adjunct faculty retention in private nonprofit universities. Available from ProQuest Dissertations \& Theses Global.

Langen, J. (2011). Evaluation of adjunct faculty in higher education institutions. Assessment \& Evaluation in Higher Education, 36(2), 185-196.

Merriam, S. B., \& Bierema, L. L. (2014). Adult learning: Linking theory and practice. San Francisco, CA: JosseyBass.

National Center for Education Statistics. (2015). Characteristics of postsecondary faculty. Retrieved from https://nces.ed.gov/programs/coe/pdf/Indicator CSC/coe CSC 2016 05.pdf

Ridge, A., \& Ritt, E. (2017). Adjunct faculty as key stakeholders in distance education. The Journal of Faculty Development, 31(2), 57-62.

Rogan, C. (2017). Growth within the adjunct faculty role: An interaction of challenge, support, and context. Available from ProQuest Dissertations \& Theses Global.

Sandhoff, D. M. (2018). Novice adjunct online faculty: Perceptions of orientation and faculty. Available from ProQuest Dissertations \& Theses Global.

Schein, E. (2004). Organizational culture and leadership. San Francisco: Jossey-Bass.

Scheive, R. J. (2014). Adjunct and full-time faculty members' satisfaction with shared governance compared to leadership styles of academic administrators. Available from ProQuest Dissertations \& Theses Global.

Schneider, S. (2015). It's time to review your adjunct employment policies. The Chronicle of Higher Education, 61(23).

Shapiro, J. P., \& Stefkovich, J. A. (2002). Ethical leadership and decision making in education: Applying theoretical perspectives to complex dilemmas. New York, NY: Routledge.

Simplicio, J. (2006). Shared governance: An analysis of power on the modern university campus from the perspective of an administrator. Education, 126(4), 763-768.

Snyder, T.D., de Brey, C., and Dillow, S.A. (2016). Digest of education statistics 2015 (NCES 2016-014). National Center for Education Statistics, Institute of Education Sciences, U.S. Department of Education. Washington, DC.

Street, S., Maisto, M., Merves, E., \& Rhoades, G. (2012). Who is professor "staff": And how can this person teach so many classes? Center for the Future of Higher Education Policy. Retrieved from https://www.insidehighered.com/sites/default/server_files/files/profstaff(2).pdf

Thedwall, K. (2008). Nontenure-track faculty: Rising numbers, lost opportunities. New Directions for Higher Education, 143, 11-19.

Tyndall, C., (2017). Called to teach: A mixed methods exploration of community college adjunct faculty's teaching self-efficacy. Available from ProQuest Dissertations \& Theses Global.

Umbach, P. D. (2007). How effective are they? Exploring the impact of contingent faculty on undergraduate education. The Review of Higher Education, 30(2), 91-123.

University of Wisconsin-Madison. (n.d.). Chapter 15 Academic Freedom. Retrieved from https://acstaff.wisc.edu/wp-content/uploads/2014/11/ASPP-Chapter-15.pdf

Waltman, J., Bergom, I., Hollenshead, C., Miller, J., \& August, L. (2012). Factors contributing to job satisfaction and dissatisfaction among non-tenure-track faculty. The Journal of Higher Education, 83(3), 411-434. 